\title{
Modeling soil water content induced by irrigation
}

\author{
Jian Xie ${ }^{1}$ \\ ${ }^{1}$ Chengdu University of Technology
}

July 29, 2020

\begin{abstract}
Infiltration and soil water content (SWC) are key concerns to agro-hydrological researchers. Understanding of irrigationinduced infiltration and soil water characteristics are fundamental to irrigation management and improving agricultural Water Use Efficiency (WUE) in arid and semi-arid areas. Based on measurements from a test site in Xinjiang, China, numerical simulations have been performed to investigate the infiltration processes under alternating drip irrigation operations. The present study focuses on simulating infiltration physics and analyzing its potential impacting factors, to shed light on the design of irrigation systems that improve WUE. The results show that irrigation schedules, surface sealing, residual water saturation, and soil fractures have significant impacts on SWC patterns for both the irrigation durations and intermittences. Low frequency irrigation with high watering rates should be avoided due to its low irrigation efficiency. Commencing with lower-rate irrigation is probably the best practice for efficient irrigation for shallow-root crops. The soil infiltrability drops exponentially or polynomially with the decrease in permeability of the immediate surface. Introduction of a 5-mm soil surface seal with a permeability of 5 $\mathrm{mD}$ leads to about $97.1 \%$ reduction in the infiltrability. Residual water saturation Swr or water content has positive correlations with Volumetric soil Water Content (VWC), due to the trapping of the residual water. Enhancement of one-fold magnitude of Swr causes $6.12 \%$ and $20.4 \%$ higher VWC for the loamy sand, but $7.57 \%$ and $5.71 \%$ lower VWC for the underlying sandy loam, at the $160 \mathrm{hr}$ and $720 \mathrm{hr}$ respectively. The presence of soil fractures leads to apparent preferential flows in the soil, which cause the wet fronts to penetrate to $115.9 \%$ and $53.88 \%$ deeper depths at the $160 \mathrm{hr}$ and $720 \mathrm{hr}$, respectively.
\end{abstract}

\section{Data Availability Statement:}

The model data for this article is available from the corresponding author on request. INTRODUCTION

Understanding of irrigation-induced infiltration and characteristics of soil water movement are fundamental to efficient management of water resources, especially for those of arid and semi-arid regions where water is scarce and crop production is critical for economic development. It is also the basis of consideration in the design, evaluation, and management of an irrigation system (Zerihun et al., 1996; Oyonarte et al., 2002). Infiltration characteristics, particularly infiltrability of cropland directly affect irrigation scheduling and water use efficiency; hence the performance of an irrigation system is strongly influenced by infiltration.

Nevertheless, these processes are much more complex than those in saturated zones, since they are involved with multiphase flow processes such as gravity- and capillary-driven moisture flow (Doughty, 1999). Despite the complexity of soil water infiltration, its impacting factors can be aggregated into two main aspects, namely soil physical properties and the time and amount of water applied (Shainberg and Singer, 1985; Shainberg et al., 1991), the latter of which actually is associated with irrigation methods and scheduling.

Numerical simulation is an ideal tool to investigate the processes of irrigation induced water infiltration and to assess the performance of various irrigation schedules, by looking into the dynamics of wetting front and the resulting distribution of SWC. The present study focuses on simulating infiltration physics and analyzing its potential influencing factors, to shed light on the design of irrigation systems that improve 
the efficiency of water use. This is of significance especially for those areas where the sustainability of the irrigated agriculture is at serious risk.

\section{METHODOLOGY}

Relative permeability curves and capillary pressure curve

Relative permeability curves and capillary pressure curve are essential tools for describing unsaturated flow in soils or other multiphase flows in geologic media. Relative permeability curves are defined by a set of functional relations typically between liquid saturation and relative permeabilities. However, capillary pressure curve is used to describe soil matric potential or capillary pressure as a function of soil water saturation. It is more frequently called Soil-Water Characteristic Curve (SWCC) for agrohydrologists or ecologists, and has been widely used for estimation of unsaturated soil properties.

In the present study, liquid relative permeability $k_{r l}$ is calculated with the van Genuchten-Mualem model (Mualem, 1976; van Genuchten, 1980). Gas relative permeability $k_{r g}$ can be calculated with the Corey's model (Corey, 1954) for $S_{g r}>0$ and the relation between $k_{r g}$ and $k_{r l}$ for $S_{g r}=0$, and both relative permeabilities are limited to the range from 0 to 1 .

$k_{\mathrm{rl}}=\{$

1 ,

$$
\sqrt{S^{*}}\left(1-\left(1-\left[S^{*}\right]^{1 / \lambda}\right)^{\lambda}\right)^{2}, \quad \mathrm{~S}_{l}<S_{\mathrm{ls}}
$$

$k_{\mathrm{rg}}=\{$

$$
\begin{array}{lc}
(1-\hat{S})^{2}\left(1-\hat{S}^{2}\right), & \mathrm{S}_{\mathrm{gr}}>0 \\
1-k_{\mathrm{rl}}, & \mathrm{S}_{\mathrm{gr}}=0
\end{array}
$$

where $S^{*}$ and $\hat{S}$ are defined by the following formulations, respectively.

$\mathrm{S}^{*}=\left(S_{l}-S_{l r}\right) /\left(S_{l s}-S_{l r}\right), \hat{S}=\left(S_{l}-S_{l r}\right) /\left(1-S_{l}-S_{g r}\right)$

$S_{l}$ and $S_{l s}$ is liquid and maximum liquid saturation, respectively; $S_{l r}$ and $S_{g r}$ is residual liquid and gaseous saturation, respectively. $\lambda$ is a parameter representing the distribution characteristics of soil pore sizes, which is $m$ in van Genuchten's notation.

Since the van Genuchten model (van Genuchten, 1980) is extensively used for describing the relation between matric potential and water saturation. The following function is employed in our study to calculate $P_{c a p}$ for SWCCs.

$P_{\text {cap }}=-P_{0}\left(\left[S^{*}\right]^{-1 / \lambda}-1\right)^{1-\lambda}(3)$

subject to the restriction $-P_{\max }[?] P_{c a p}[?] 0$.

\section{Numerical simulator}

The numerical simulator used for the simulations in this study is the EOS3 module of the integral finite difference code named TOUGH2 (Pruess et al., 1999). TOUGH2 has been used successfully in many geothermal and nuclear waste disposal studies (e.g., Sonnenthal and Bodvarsson, 1999; Haukwa et al., 2003). The EOS3 module of the code is developed for simulating the transport processes of water, air, and heat in porous media. As a result, it can be used to simulate unsaturated infiltration in soil.

\section{CONCEPTUAL MODEL AND MODEL GRID}

A loamy sand tillage plot typically in arid regions of northwest China is considered for the present study. The irrigation rate from each nozzle is assumed to be $6.94 \times 10^{-4} \mathrm{~kg} / \mathrm{s} \cdot \mathrm{m}^{2}$ for the base case (C0; cf. Table 1) and the infiltration presumably occurs with the same rate, given that the soil is mostly dry in arid environment. 
The irrigation is delivered using a sprinkling irrigation system, with the nozzles having spraying radius of 0.1 $\mathrm{m}$ and horizontal spacing of $0.3 \mathrm{~m}$. The irrigation water is assumed to be uniformly applied to the surface of the entire circular area. Although there is supposed to be 38 nozzles in a length of $11.2 \mathrm{~m}$ in reality, only 3 nozzles are considered in the model domain for simplicity, as illustrated in Fig. 1. The VWCs for each depth interval of $0.1 \mathrm{~m}$ inside the block of interest (BOI) are calculated for analysis based on the numerical simulations.

The numerical code TOUGH2/EOS3 was chosen to simulate the processes of soil imbibitions under infiltration induced by irrigation, as well as of water redistribution due to drainage in the irrigation intermittence. The lateral range and the depth of the model geometry are $11.2 \mathrm{~m}$ and $2.1 \mathrm{~m}$, respectively (Fig. 1). The grid size ranges in horizontal from $0.1 \mathrm{~m}$ close to the nozzle gradually up to $0.4 \mathrm{~m}$ at the periphery. The grid refining interval is roughly between 480 and $660 \mathrm{~cm}$ of the $\mathrm{X}$ coordinate, particularly in the vicinity of 0.3 $\mathrm{m}$ of the nozzles. The resulting mesh has 800 elements and 2170 connections.

Since TOUGH2/EOS3 uses phase saturation as output, liquid saturation, approximately equal to water saturation $S_{w}$, is converted in some cases to VWC using the following formulation:

$\mathrm{VWC}=S_{w} \cdot(4)$

The intrinsic permeability required for the current simulator is calculated with the following formulation, since only the measurement of saturated hydraulic conductivity $k_{s}$ is available in the previous studies (Wang, $2013 ; \mathrm{Li}, 2014)$.

$K_{h}=\frac{\mu k_{s}}{\rho \gamma}(5)$

Here, $K_{h}$ denotes horizontal intrinsic permeability $\left[\mathrm{m}^{2}\right], \mu$ is dynamic viscosity $[\mathrm{Pa} \cdot \mathrm{s}]$, and the others are found in the above text.

Figure1. Grid design of the model.

\section{SIMULATION SCHEME AND MODEL ASSIGNMENT}

\section{Simulation cases and parameterization}

The base case $\mathrm{C} 0$ of the model is a 'benchmark' simulation of infiltration induced by drip irrigation in the irrigation schedule coded IS1. The irrigation rate of the nozzle for C0 is determined according to Li (2014). For the purpose of analyzing the potential factors influencing the soil water content in the vadose zone, four additional simulation cases (C1-C4) encompassing 11 sub-cases (scenarios) were investigated to look into the effects on soil water distribution of the irrigation schedule, soil surface seal, residual water saturation, and preferential flow. Besides IS1 for C0, C1 considers additional 5 ISs: (i) IS1, 6-hr irrigation per day at an irrigation rate of $6.94 \times 10^{-4} \mathrm{~kg} / \mathrm{s}$ every 6 days; (ii) IS2, 5 -hr irrigation per day at an irrigation rate of $6.94 \times 10^{-4} \mathrm{~kg} / \mathrm{s}$ every 5 days; (iii) IS3, 3-hr irrigation per day at an irrigation rate of $6.94 \times 10^{-4} \mathrm{~kg} / \mathrm{s}$ every 3 days; (iv) IS4, 3-hr irrigation per day at an irrigation rate of $1.388 \times 10^{-3} \mathrm{~kg} / \mathrm{s}$ every 6 days; (v) IS5, 6-hr irrigation per day at an exponentially reducing irrigation rate every 6 days; (vi) IS6, 6-hr irrigation per day at an exponentially increasing irrigation rate every 6 days. More concrete details are found in Fig. 2.

$\mathrm{C} 2$ was designed to investigate the effects of soil surface seal on water infiltration. A surface seal of $5 \mathrm{~mm}$ thick is included in this case, to simulate surface crust formed by raindrops splash or soil salinization. C3 run the exactly same model as $\mathrm{C} 0$ but using differing residual water saturations to investigate the effect on infiltration. Preferential flow was simulated in $\mathrm{C} 4$ by introducing a set of synthesized fractures in the soil profile.

The hydraulic properties for these simulation cases or scenarios are presented in Table 1 or described later when analyzing specific cases. The assignment of soil properties such as porosity, permeability and grain density are based on actual measurements from the field test site (Wang, 2013). The relations of relative permeabilities and capillary pressures with liquid-phase saturation are described with the van GenuchtenMualem function (Mualem, 1976; van Genuchten, 1980) and the van Genuchten function (van Genuchten, 
1980), respectively. The corresponding curves assembled with parameters from the experiments in Wang (2013) and Li (2014) are illustrated in Fig. 3.

Table 1. Major soil properties used for the base-case simulation.

Figure 2. Irrigation schedules considered in the model.

Figure 3 . The relative permeability (a-c) and capillary pressure curves (d) defined for the three soils for the base-case simulation.

\section{Boundary and initial conditions}

As is illustrated in Fig. 1, the top of the model is the ground surface, so the upper boundary of the model is set with constant pressure (1.0 bar). The lateral boundaries are regarded as non-flow since they are vertical and hence parallel to the flow direction of the infiltrated water in vadose zone, which is well known to be predominately vertical. The initial water table is located at the depth of $2 \mathrm{~m}$ in our simulations, since the actual water tables in the test site were observed to be mostly in the range of $1.6^{\sim} 2.3 \mathrm{~m}$ below the surface (Wang, 2013). The lower boundary is defined as a non-flow boundary, allowing for elevation in the phreatic surface in case percolation occurs from the unsaturated zone.

To simulate a fairly dry condition, the initial $S_{W}$ is set to be 0.2 for all the model grid cells for C0. The temperature is simply taken to be $23{ }^{\circ} \mathrm{C}$ throughout the model domain and isothermal processes are modeled for all the cases. The initial pore pressure is set as 0.91 bar.

\section{ANALYSIS OF THE BASE-CASE SIMULATION RESULTS}

\section{Migration of infiltrated water}

Infiltration of irrigation water accompanies advance of the wet front and causes changes in soil water content. Fig. 4 presents the simulated VWC plumes of $\mathrm{C} 0$ for analyzing the soil wetting process under irrigation, and Fig. 5 shows the counter parts during the intermittences of irrigation, to shed light on the process of water redistribution. At the early times after the irrigation was applied, the soil sucks water into the pores very quickly since the matric potential is large for a drying condition. The superficial soil under the irrigation points (i.e. nozzles) becomes saturated due to the infiltration. The saturated soil has a VWC of 0.40 , which is exactly the value of porosity of the loamy sand, since we set a zero residual gas saturation to ensure easier infiltration. The soil immediately inside the wet front is wet yet unsaturated and hence still contains gases in pores. The wetting front advances downward in the drive of gravity and matric potential. The water under the middle nozzle flows downward more quickly than its both sides, leading to forming a typical tongue-alike wet plume, although the shape of the plume is also somewhat affected by the grid geometry. This phenomenon occurs in a two-phase flow domain since the infiltrated water flow is hindered to some extent by the displaced air, causing the air migrates from the beneath to the upper outside.

The wet front develops downward with the time elapsed, no matter when there is irrigation or not. After $6 \mathrm{hrs}$ of irrigation, i.e. at $\mathrm{t}=16 \mathrm{hr}$, the wet front arrives at depth of $0.35 \mathrm{~m}$. At the $720 \mathrm{hr}$, the wet front advances to approximately $1.20-\mathrm{m}$ depth, which is the lower boundary of the sandy loam. The wetting depths at the other times are found in Fig. 4 and Fig. 5. Due to the infiltration, after the last-time irrigation at the $592 \mathrm{hr}$, the soil under the three irrigation nozzles has a planar wetting scope of $1.08 \mathrm{~m}(517-625 \mathrm{~cm}$, Fig. 4) at the surface and $1.73 \mathrm{~m}(492-665 \mathrm{~cm}$, Fig. 4) in the sandy loam. The corresponding values at the $720 \mathrm{hr}$ are almost the same (Fig. 5) since the water redistribution basically only changes the wetting depth. It is also found, by comparing the plumes in Fig. 4 and Fig. 5, that the VWC in the topsoil (loamy sand) is obviously higher than the subsoil (sandy loam) under the condition of irrigation. In contrast, opposite characteristics are observed during the irrigation intermittences. The significantly higher VWC in the subsoil indicates that the soil water migration after the irrigation ceased led to the water redistribution and increased wetting depth (Fig. 5). It is straightforward to conclude that the infiltration is dominantly a vertical process that the wet front advances under the combined control of gravity and matric potential.

Figure 4. Vertical plumes of VWC for the base case C0 (IS1) at various times under irrigation. 
Figure 5. Vertical plumes of VWC for the base case C0 (IS1) during the irrigation intermittences.

\section{The dynamics of $V W C$}

Fig. 6a and b analyze the dynamics of VWC on a 10-thick layer basis. For each layer, the VWC varies with time for each layer and has high values after irrigation for the upper $0.6 \mathrm{~m}$ of soil. The response of VWC to irrigation decays with depth and manifests an increasing hysteretic effect with depth. This increase in hysteresis is an indicator of the average velocity of the wet front. Note also that the time lag becomes shorter at later times for each layer. For instance, the picks of VWC for the depth $0.4^{\sim} 0.5 \mathrm{~m}$ appear $80 \mathrm{hrs}$ later than irrigation at about the $240 \mathrm{hr}$, as is illustrated in Fig. 8a. However, the time lag turns to be $40 \mathrm{hrs}$ at about the $480 \mathrm{hr}$. This variation in the time lag for a specific layer indicates a faster arrival of the wet front at the later time, due to gradually increased area of the saturated or non-deficit zones.

The infiltration induced by irrigation causes soil water dynamics different between the upper and lower half of the thickness of the soil. The upper soil has higher VWCs than the lower when the infiltrated water has not arrived there yet. The VWC of the lower soil starts with a level of almost deficit and is elevated by irrigation layer by layer, which is supposed to be a reasonable and common situation in dry episodes of arid zones.

Since the VWCs in Fig. 6a and b are calculated on a layer basis at various discrete points of time, it is quite necessary to check out some specific locations for more consecutive and hence more accurate illustration of VWC dynamics. Fig. 6c and d present the variation of VWC at 10 selected positions in the ten intervals of depth counted in Fig. 6a and b. Periodic imbibitions and water recessions of soil pore are observed more clearly in these curves. The soil pores are increasingly saturated with water under and after irrigation, and then dewatered in the intermittences of irrigation due to pore drainage. The relatively sharp and gentle slopes of the dynamic curves are indicative of fast and easy infiltration whereas relatively slower and harder drainage (Fig. 6c). The regimes of VWC dynamics for the lower specific positions are basically similar to those for depth intervals (Fig. 6d). Analysis of infiltration and soil water dynamics based on point observations is thus well justified and meaningful for agricultural or hydrological research.

Figure 6. Temporal variation of the average VWCs of each depth interval in the BOI (a-b) and VWCs at selected individual positions (c-d). The irrigation rate IR applied is plotted as bars for convenience of analysis.

\section{DISCUSSION}

\section{Effects of irrigation schedule}

Evaluation and improvement of WUE have become important issues for agricultural water management. Looking for an optimum irrigation strategy for a specific environment to promote the WUE will be important for saving water resources in this region. Six irrigation schedules have been investigated to save water resources and improve irrigation efficiency. Fig. 7 and Fig. 8 compare the VWC plumes between these six strategies (IS1-IS6) at the $160 \mathrm{hr}$ and $720 \mathrm{hr}$, respectively. The plumes for the six schedules have hardly notable differences in terms of the shape and size, since they are subject to identical total amount of infiltrated irrigation water. However, differing irrigation schedules result in considerably differing soil VWCs no matter in the irrigation durations or in the intermittences. As has mentioned before, the IS for C0 (i.e. IS1) is 6 consecutive hours of irrigation per day every 6 days at the rate of $6.944 \times 10^{-4} \mathrm{~kg} / \mathrm{s}$. The VWCs for IS3 and IS4 have significantly lower values than the others, indicating that these two ISs have lower irrigation efficiencies than the other four schedules, and IS4 leads to the lowest efficiency. This is because of their lengthy intermittences between irrigations. The VWCs turn to particularly low during these long post-irrigation periods. IS2 has relatively low VWCs at $160 \mathrm{hrs}$ since that time is free of irrigation. Only marginally higher VWCs are observed at $720 \mathrm{hrs}$ in Fig. 9d. For IS5 and IS6, the VWCs only have subtle differences than C0 and between each other. Higher VWCs can be observed under irrigation for IS6 than for IS5, due to the increasing IR applied for IS6. This indicates that commencing with lower-rate irrigation is likely instrumental to enhancing WUE since it favors gradual saturation of upper soil pores, avoiding quick loss of water by 
leaking down to the deep depths.

In order to take a closer look at the potential differences in the VWC distributions between the ISs, vertical profiles of VWC between the six ISs at four typical times have been plotted in Fig. 9. At $16 \mathrm{hrs,} \mathrm{when} \mathrm{the}$ first day irrigation has completed for all six ISs, the VWC shows minor difference between ISs except for IS3 because of its less irrigation amount by that time. The IS4 causes slightly higher VWC in the upper part of the loamy sand and, the IS2 and IS6 result in slightly lower VWC in the same horizons. However, at the 160 hr, the VWC profiles for IS2, IS3 and IS4 show striking differences from C0 and others. Same characteristic has been observed in Fig. 9b. The lower VWCs above the depth of $30 \mathrm{~cm}$ for IS2 and IS3 can be explained by the actually less irrigation amount of water than the others. The slightly higher VWC between the depth $30^{\sim} 60 \mathrm{~cm}$ for IS2 is supposed to be a result of faster migration due to relatively more frequent irrigation. The particularly low VWC above the depth of $40 \mathrm{~cm}$ for IS4 for the $16 \mathrm{hr}$ latter on, is attributed to its low frequency of irrigation. Application of the IS2 and IS6 leads to approximately same VWCs in the latter hours of the investigated duration (Fig. 9c and d). From a perspective of water saving, relatively high VWC in the root zone and low leak of water into the lower depths favors water uptake by crop roots and thereby higher irrigation efficiency. Of the six ISs examined, our simulations show that IS6 is probably the best practice for efficient irrigation for shallow-root crops. The IS5 and even IS2 may be comparable to IS1 in terms of irrigation efficiency. The IS4 would be the last option for agricultural irrigation, especially for shallow-root crops in arid areas.

Figure 7. Comparison of the vertical plumes of VWC between six irrigation schedules (IS1-IS6) at the 160 hr.

Figure 8. Comparison of the vertical plumes of VWC between six irrigation schedules (IS1-IS6) at the 720 hr.

Figure 9. Comparison of vertical profiles of VWC between six irrigation schedules (IS1-IS6) at various times.

\section{Effects of surface seal}

Soil surface seal can be formed due to reasons like surface crusting, salinization, or reduced tilth. The thickness of the seal is typically $5 \mathrm{~mm}$, as is specified for C2. Formation of soil surface seal may cause lower porosity, reduced infiltration capacity, and decreased irrigation efficiency (Souza et al., 2014; Hardie and Almajmaie, 2019). To investigate the effects of the seal on water infiltration and soil water distribution, four additional simulations had been run with much lower permeabilities for the topmost $5 \mathrm{~mm}$-layer compared to that for $\mathrm{C} 0$. The simulation runs with various low permeabilities cause convergence failure at different times. Since the permeability of the surface seal is the only parameter subject to change, it can be responsible for the convergence failure. Therefore, the infiltrability (i.e. infiltration capacity) of the soil surface can be simply determined by such a method known as 'try-and-error'. Accurate quantification of infiltration is essential for irrigation system design, irrigation scheduling and irrigation systems optimization and management.

Fig. 10 illustrates the infiltrabiliy as a function of the permeability of the seal. The infiltrability for C0 (i.e. without seal) is $1.05 \times 10^{-3} \mathrm{~kg} / \mathrm{s}$, which is $51 \%$ greater than the actual infiltration rate applied for this case. As is shown in Fig. 10, the infiltrability drops exponentially or polynomially with the decrease in permeability of the surface. The infiltrability for a permeability of $5 \mathrm{mD}$, which is a typical order of magnitude for developed seals of soil surface according to McIntyre (1958), is about $97.1 \%$ lower than that for C0. This result is comparable to $93.0 \%$ as has been proposed by Hardie and Almajmaie (2019). However, it is far higher than $40 \sim 50 \%$ that have been reported by previous studies (e.g., Eisenhauer, 1984; Bu et al., 2014). It should be noted that to what extent the soil surface seal affects infiltration, largely depends on how large the permeability of the superficial soil will be altered due to the formation of the seal, and the rate of rainfall or irrigation. It is straightforward that low-permeability soils are expected to have smaller changes in infiltrability once they have seals on the surface. The relatively high permeability of loamy sand before surface sealing in this study is thought to be the primary reason for the tremendous reduction in the infiltration. Furthermore, overestimation of porosity of the seal due to sampling difficulty is a normal reason for underestimation of infiltration reduction based on sampling tests (Hardie and Almajmaie, 2019). Last 
but not least, numerical simulation can hardly describe the integrity of the seal, which however is probably quite common for actual cases. When the permeability of the superficial horizon becomes lower than roughly $500 \mathrm{mD}$, the infiltrability of the soil tends to decrease slowly, and when the permeability is below $100 \mathrm{mD}$, the infiltrability becomes marginal.

Fig. 11 assists in a further step to identify the impacts of soil surface seal on infiltration. It can be seen that the infiltration through the tillage layer is strongly controlled by the surface seal. The ' $1410 \mathrm{mD}$ ' in the legend corresponds to the permeability of the surface layer for $\mathrm{C} 0$, as is illustrated in the figure, reduced permeabilities for the additional cases render remarkably lower VWCs along the depth, except for the case ' $775.5 \mathrm{mD}$ ' in the early times. This can be an effect analogous to soil water redistribution. Reduced permeability caused weak infiltration and dominant redistribution of the soil water. Nevertheless, if the permeability of the surface seal is extremely low, the soil can be pretty dry, as is demonstrated in Fig. 11. The presence of soil surface seal hinders infiltration and greatly reduces saturation of soil, which will further lower hydraulic conductivity as low as 1/2000 folds, as have been proposed by some scholars (e.g. McIntyre, 1958).

For our simulation cases in Fig. 11, introduction of a surface seal with permeability of $140 \mathrm{mD}$ causes change in VWC from 0.21 to lower than 0.15 for the loamy sand under irrigation.

Figure 10. The infiltrabilities of soil for various cases of permeability of the surface crust considered.

Figure 11. Comparison of vertical profiles of VWC between cases with differing permeabilities of soil surface seal at various times.

\section{Effects of residual water saturation}

Residual water saturation $S_{w r}$ or water content ${ }_{r}$ is a hydraulic parameter defining SWCC. It is dependent on various factors such as soil organic carbon and clay content as well as other soil physical properties (e.g., Qin, 2003; Poeplau et al., 2015). Soil with different $S_{w r}$ is expected to have different pattern of SWC. Besides C0, additional two simulations with differing designation of $S_{w r}$ were run to investigate this effect. The differences in the profiles of VWC due to differing $S_{w r}$ are clearly seen in Fig. 12. The curve for C0 is in the between of the other two lines at the four times, because of its $S_{w r}$ has a value between the other both. Higher $S_{w r}$ allows more water to be retained in the pores and cannot be driven out by soil gases. This explains why higher $S_{w r}$ leads to higher VWC especially for the times free of irrigation (Fig. 12c, d). Enhancement of one-fold magnitude of $S_{w r}$ causes $6.12 \%$ and $20.4 \%$ higher VWC for the loamy sand, but $7.57 \%$ and $5.71 \%$ lower VWC for the underlying sandy loam, at the $160 \mathrm{hr}$ and $720 \mathrm{hr}$ respectively. Given a certain irrigation water amount, fast downward migration of the wet front and higher SWC in deep horizons are implications of low irrigation water use efficiency. High residual water saturation in the root zone benefits crop growth during rainless periods. Speaking in this sense, it is encouraged to take practical measures to alter the soil structure and physical properties (e.g. the organic content) to ensure a higher $S_{w r}$ in the root zone of the crops.

Figure 12. Profiles of VWC at various times for differing residual water saturation settings for the loamy sand $\left(\mathrm{C} 0: \mathrm{S}_{\mathrm{wr}}=0.135 ; \mathrm{C} 30: \mathrm{S}_{\mathrm{wr}}=0.067 ; \mathrm{C} 31: \mathrm{S}_{\mathrm{wr}}=0.270\right)$.

\section{Effects of preferential flow}

Heterogeneity of land soils with respect to porosity and permeability can arise from a bunch of pedologic features or anthropologic activities, including soil fractures, macropores formed by rotten roots and/or earthworms, surface crust, soil tillage, and among others (Gerke and Genuchten, 1993; Cuthbert et al., 2013). In dry environment, soil fractures are particularly common in numerous farmlands as soil shrinks due to water loss. These fractures and/or macropores form hydraulic conduits for preferential flow, which is very common in unsaturated soils. Presence of preferential paths in soil generally compromises irrigation efficiency, due to the 'bypass flow' in them without necessity to fill deficit in topsoil matrix (Cuthbert et al., 2013). Despite the known effects of soil heterogeneity on soil water distribution and groundwater, soil preferential paths are rarely accounted for irrigation evaluations. 
Fig. 13 and Fig. 14 present vertical plumes of VWC for $\mathrm{C} 4$ under irrigation and in the intermittence of irrigation, respectively. The configuration of the fractures in the soil has been presented in Fig. 1. The porosity and permeability of the fractures is assumed to be 0.9 and 100 Darcy, respectively. Ideally, the infiltrated water travels downward and saturates the soil successively in a known 'tipping bucket' fashion (Emerman, 1995). This means that excess water flows to deeper layers when the soil moisture level reaches saturation. The presence of soil fractures for $\mathrm{C} 4$ leads to complex distribution of VWC, which is characterized by apparent preferential flows along the fractures in the soil, as illustrated in Fig. 13 and Fig. 14 as well. VWCs that is as high as 0.491 are observed in the fracture network under condition of irrigation. The values, however, change to 0.457 when there is free of irrigation, due to water redistribution. It should be noted that relatively high VWCs are also observed in some of the matrix pores close to the fractures. This is due to the matrix imbibition of fracture flow under the function of the capillary pressure gradient between the matrix pores and fracture apertures.

The VWC plumes have more irregular forms due to uneven wet fronts induced by preferential flows. The wet front for $\mathrm{C} 4$ penetrates to the depth of $1.35 \mathrm{~m}$ at the $160 \mathrm{hr}$ and $1.89 \mathrm{~m}$ at the $720 \mathrm{hr}$ respectively, which is $115.9 \%$ and $53.88 \%$ deeper than that for $\mathrm{C} 0$, only due to the presence of preferential flow through the fractures. The infiltrated water travels as fast as $0.2 \mathrm{~m}$ per day through preferential pathways in our model. It should be noted that the configuration of fractures or cracks are expected to have substantial effects on the local water movement in soil. This topic, however, is beyond the scope of the present study.

To further look into the effects of preferential flow on SWC, in Fig. 15 the profiles of VWC are plotted for $\mathrm{C} 0$ and $\mathrm{C} 4$ at the four selected times. The soil with fractures has relatively higher VWC at lower depths in the early time (Fig. 15a, b), due to deeper wet fronts formed by faster movement of preferential flow. However, since we only calculate the VWCs for the BOI, the soil within depth of $1.0 \mathrm{~m}$ becomes drier at the later times for $\mathrm{C} 4$ than that for $\mathrm{C} 0$ (Fig. 15c, d), because a portion of water has traveled down to below the lower boundary of the BOI (i.e. $1.0 \mathrm{~m}$ ).

Figure 13. Vertical plumes of VWC for the case $\mathrm{C} 4$ at various times under irrigation.

Figure 14. Vertical plumes of VWC for the case $\mathrm{C} 4$ at various times during the irrigation intermittences.

Figure 15. Vertical profiles of VWC for $\mathrm{C} 4$ in comparison with $\mathrm{C} 0$ at various times.

\section{SUMMARY AND CONCLUSIONS}

Numerical simulations have been performed to analyze irrigation induced infiltration and soil water distribution. Factors influencing these processes and behaviors are identified by a set of scenario investigations. It is concluded that irrigation schedule, surface seal, residual water saturation, and soil heterogeneity can impose significant impacts on water infiltration and the resulting soil water regime. Recognition of these processes and mechanisms favors irrigation design and water management by improving soil conditions and optimizing irrigation strategies. Major findings are summarized as follows for the reader's convenience.

(1) Irrigation schedules have significant impacts on SWC patterns for both the irrigation durations and intermittences. The VWCs for IS3 and IS4 have lower irrigation efficiencies than the other four schedules, due to their lengthy intermittences between irrigations. Commencing with lower-rate irrigation is likely instrumental to enhancing WUE since it favors saturating the upper soil pores to the largest extent, avoiding quick loss of water by leaking down to the deep depths. Of the six ISs examined, our simulations show that IS6 is probably the best practice for efficient irrigation for shallow-root crops. The IS5 and even IS2 may be comparable to IS1 in terms of irrigation efficiency. The IS4 would be the last option for agricultural irrigation, especially for shallow-root crops in arid areas.

(2) The infiltrability of the soil surface was determined by a bunch of 'try-and-error' simulations. The infiltrability drops exponentially or polynomially with the decrease in permeability of the immediate surface. Introduction of 5 -mm soil surface seal with a permeability of $5 \mathrm{mD}$ leads to about $97.1 \%$ reduction in the infiltrability. The strong effect on the infiltration of the surface seal is mainly due to the relatively high permeability of the loamy sand. The presence of soil surface seal hinders infiltration and hence renders 
remarkably lower VWCs along the depth. Exceptions can be observed in case the surface sealing is poorly developed.

(3) Residual water saturation or water content has positive correlations with VWC, due to the entrapment of the residual water. Higher $S_{w r}$ leads to higher VWC especially for the times free of irrigation. Enhancement of one-fold magnitude of $S_{w r}$ causes $6.12 \%$ and $20.4 \%$ higher VWC for the loamy sand, but $7.57 \%$ and $5.71 \%$ lower VWC for the underlying sandy loam, at the $160 \mathrm{hr}$ and $720 \mathrm{hr}$ respectively. It is encouraged to take practical measures to alter the soil structure and physical properties to ensure a higher $S_{w r}$ in the root zone of the crops.

(4) The presence of soil fractures for C4 leads to apparent preferential flows along the fractures in the soil. VWCs that is as high as 0.491 are observed in the fracture network under condition of irrigation. The VWC plumes have more irregular forms due to uneven wet fronts induced by preferential flows. The presence of preferential flow causes the wet fronts to penetrate to $115.9 \%$ and $53.88 \%$ deeper depths at the $160 \mathrm{hr}$ and $720 \mathrm{hr}$, respectively. Thus the presence of preferential flows in the soil can cause a loss of irrigated water and hence lower irrigation efficiency. The infiltrated water travels as fast as $0.2 \mathrm{~m}$ per day through preferential pathways in our model.

\section{ACKNOWLEDGMENTS}

This study is funded by CDUT Talent Grant (Grant No. KYQD6435). The authors would like to acknowledge ... anonymous reviewers for their constructional suggestions. Discussions with my colleague Dr. Zaimin Wang of Chengdu University of Technology are beneficial to the construction of the model in this paper.

\section{REFERENCES}

ASTM, 2009. Standard D3385-09. Standard Test Method for Infiltration Rate of Soils in Field Using Double-Ring Infiltrometer. ASTM International, West Conshohocken, PA.

Brooks, R.H., Corey, A.T., 1964. Hydraulic properties of porous media. Hydrology Paper 3. Colorado State University, Fort Collins.

Bu, C-f., Wu, S-f., Yang, K-b., 2014. Effects of physical soil crusts on infiltration and splash erosion in three typical Chinese soils. International Journal of Sediment Research 29, 491-501.

Corey, A.T., 1954. The interrelation between gas and oil relative permeabilities, Producers Monthly, 38-41.

Cuthbert, M.O., Mackay, R., Nimmo, J.R., 2013. Linking soil moisture balance and source-responsive models to estimate diffuse and preferential components of groundwater recharge. Hydrol. Earth Syst. Sci. Discuss. 17, 1003-1019.

Cuthbert, M.O., Tindimugaya, C., 2010. The importance of preferential flow in controlling groundwater recharge in tropical Africa and implications for modelling the impact of climate change on groundwater resources. J. Water Clim. Change 1, 234-245.

Doughty, C., 1999. Investigation of conceptual and numerical approaches for evaluating moisture, gas, chemical, and heat transport in fractured unsaturated rock. Journal of Contaminant Hydrology 38, 69-106.

Emerman, S.H., 1995. The tipping bucket equations as a model for macropore flow. Journal of Hydrology $171,23-47$.

Eisenhauer, D.E., 1984. Surface sealing and infiltration with surface irrigation. PhD dissertation, Colorado State University, Ft. Collins, CO.

Fredlund, D.G., Rahardjo, H., 1993. Soil Mechanics for Unsaturated Soils. Wiley, New York, NY, USA.

Gerke, H.H., Genuchten, M.T.V., 1993. A dual-porosity model for simulating the preferential movement of water and solutes in structured porous media. Water Resour. Res. 29 (2), 305-319. 
Hardie, M., Almajmaie, A., 2019. Measuring and estimating the hydrological properties of a soil crust. Journal of Hydrology 574, 12-22.

Haukwa, C.B., Wu, Y.-S., Bodvarsson, G.S., 2003. Modeling thermal-hydrological response of the unsaturated zone at Yucca Mountain, Nevada, to thermal load at a potential repository. Journal of Contaminant Hydrology $62-63,529-552$.

Helalia, A.M., Letey, J., Graham, R.C., 1988. Crust formation and clay migration effects on infiltration rate. Soil Sci. Soc. Am. J. 52, 251-255.

Li, X., 2014. Soil water flow system of mulched drip irrigation with brackish water and its application in an arid region. Dissertation submitted to China University of Geosciences (Wuhan).

McIntyre, D.S., 1958. Permeability measurements of soil crusts formed by raindrop impact. Soil Sci. 85 (4), $185-189$.

Morin, J., Van Winkel, J., 1996. The effect of raindrop impact and sheet erosion on infiltration rate and crust formation. Soil Sci. Soc. Am. J. 60, 1223-1227.

Nimmo, J. R., 2010. Theory for source-responsive and free-surface film modeling of unsaturated flow. Vadose Zone J. 9, 295-306.

Nimmo, J. R., Mitchell, L., 2013. Predicting vertically nonsequential wetting patterns with a sourceresponsive model. Vadose Zone J. 9, 295-306.

Oyonarte, N.A., Mateos, L., Palomo, M.J., 2002. Infiltration variability in furrow irrigation. J. Irrig. Drain. Eng. ASCE 128, 26-33.

Poeplau, C., Eriksson, J., Kätterer, T., 2015. Estimating residual water content in air-dried soil from organic carbon and clay content. Soil \& Tillage Research 145, 181-183.

Pruess, K., Oldenburg, C., Moridis, G., 1999. TOUGH2 User's Guide, Version 2.0. Lawrence Berkeley National Laboratory, Berkeley, CA.

Qin, Y.-D., 2003. Soil physics. Higher Education Press, Beijing.

Shainberg I; Gal M; Ferreira A G; Goldstein D (1991). Effect of water quality and amendments on the hydraulic properties and erosion from several Mediterranean soils. Soil Technology, 4, 135-146.

Shainberg, I., Singer, M.J., 1985. Effects of electrolyte concentration on the hydraulic properties of depositional crust. Soil Science Society of America Journal, 49, 1260-1263.

Sonnenthal, E.L., Bodvarsson, G.S., 1999. Constraints on the hydrology of the unsaturated zone at Yucca Mountain, NV from three-dimensional models of chloride and strontium geochemistry. Journal of Contaminant Hydrology 38, 107-156.

Souza, E.S., Antonino, A.C.D., Heck, R.J., Montenegro, S.M.G.L., Lima, J.R.S., Sampaio, E.V.S.B., AnguloJaramillo, R., Vauclin, M., 2014. Effect of crusting on the physical and hydraulic properties of a soil cropped with Castor beans (Ricinus communis L.) in the northeastern region of Brazil. Soil Tillage Res. 141, 55-61.

van Genuchten, M.T., 1980. A closed form equation for predicting the hydraulic conductivity of unsaturated soils. Soil Sci. Soc. Am. J. 44, 892-898.

Wang, Z., 2013. Study on the cotton-water-solute interactions under mulched drip irrigation with brackish water in an arid area. Dissertation submitted to China University of Geosciences (Wuhan).

Zerihun, D., Feyen, J., Reddy, J.M., 1996. Sensitivity analysis of furrow-irrigation performance parameters. J. Irrig. Drain. Eng. ASCE 122, 49-57.

\section{Hosted file}


Infiltration-HP-figures.docx available at https://authorea.com/users/347057/articles/472885modeling-soil-water-content-induced-by-irrigation

\section{Hosted file}

Infiltration-HP-table.docx available at https://authorea.com/users/347057/articles/472885modeling-soil-water-content-induced-by-irrigation 